\title{
REFLECTION
}

\section{When Practice Transformation Impedes Practice Improvement}

\author{
Edward Bujold, MD, FAAFP \\ Private Practice, Caldwell County, North \\ Carolina
}

\begin{abstract}
I lead a small practice in rural western North Carolina. We have embraced the patient-centered medical home model and other practice-improvement initiatives, and I have seen our practice transformed in many positive ways. But in the past year alone, my staff and I have spent hundreds of hours studying for and taking exams, certifying for numerous programs, and updating our electronic health records system (EHR) to meet new national requirements and then relearning our EHR. Seeing patients used to be the hardest part of my job. It is now the easiest by far. I am considering walking away from the time-intensive PCMH certification even though it would cause financial hardship. We have more important business at hand-taking excellent care of patients, improving our practice, and meaningfully engaging with our patients.
\end{abstract}

Ann Fam Med 2015;13:273-275. doi: 10.1370/afm.1789.

0 eeing patients used to be the hardest part of my job. It is now the easiest by a long shot. It is the time when I really feel most alive. I remember Michael Jordan once said the only peace he found was on the basketball court. I can relate.

Today, the hardest part of my job is obtaining and maintaining multiple certifications and ensuring that I meet Meaningful Use standards. In the past year alone, my staff and I spent hundreds of hours studying for and taking exams, certifying for numerous programs, and updating then relearning our EHR to meet meaningful use requirements. This was time we could have spent in patient care or pursuing outside interests designed to nurture our physical and mental wellbeing — the fourth pillar of the Quadruple Aim: improving the health of populations, enhancing the patient experience, reducing the per capita cost of health care, and improving the work life of health care providers, including clinicians and staff.' My staff and I have fully embraced the transformation of our clinic into a high-functioning patient-centered medical home, but it is time to reassess the effort we must devote to demonstrating the quality we have achieved to the powers that be.

I lead a small practice with 1 physician (me) and 2 nurse practitioners in western North Carolina. We are in a fairly rural community nestled in the foothills of the Appalachian Mountains. I have 13 employees, including a pharmacist (PharmD), a PhD psychologist, and a physical therapist. We practice a full range of primary care, excluding obstetrics, and we continue to take care of patients in the hospital. My staff has embraced the patientcentered medical home model $(\mathrm{PCMH}){ }^{2}$ and over the past 5 years I have seen our practice transformed. Because all members of our clinic now work to the highest level of their job descriptions, our transformation has increased our efficiency, allowed us to see more patients in a timely fashion, and improve our gross and net revenue. My staff and I are much happier. My staff feels they are part of a true team. Each member of the staff now feels his or her contributions to the team make a difference in our 
patients' health care. I will never again make a major decision in our clinic without first getting input from our entire team. Team members now feel their opinions matter. This process has empowered them to be better employees, and I have seen my staff grow personally and professionally as a result of our transformation. The health of our population has improved and, by focusing on patient needs, our hospitalization rates are down $80 \%$ over the last 5 years. Every day my staff sees the impact the transformation has made in the health of our patient population, and it is a source of great pride.

My practice has been actively involved in primary care research for more than 20 years. Recently, I participated in Patient Centered Outcomes Research Institute activities, and I am involved in a couple of North American Primary Care Research Group initiatives. I am a member of the American Academy of Family Physicians' National Research Network Advisory Board and recently have been named the Chief Medical Officer of KPN Health Analytics, a data extraction company working with physician practices, accountable care organizations, and health information exchanges. Our work with local manufacturers to lower their health care costs has been recognized by the Patient Centered Primary Care Collaborative (PCPCC). Participation in these organizations has helped my practice to be at the forefront of PCMH transformation. As a result of these collaborations, I am exposed to thought leaders, heads of government agencies involved in health care, and academic colleagues interested in practice improvement and transformation. I am able to bring many ideas back to my practice and implement changes that enable my staff to care for our patients in a more efficient, effective manner.

Unfortunately, becoming a $\mathrm{PCMH}$ and proving it are 2 different tasks. As much as my staff and I embrace practice transformation, documenting that we have made this transformation has become a burden that is now preventing further practice improvement. Last year alone we certified with National Committee for Quality Assurance (NCQA) as a level III PCMH, achieved recognition in their stroke/coronary artery disease and diabetes recognition programs and demonstrated Stage 2 Meaningful Use. ${ }^{3}$ In addition, I took my family medicine board exam and become certified as a Department of Transportation physician examiner for the first time.

One thing we wanted to do last year was set up a patient engagement/advocacy committee for our clinic and community. I have big plans for this committee, because I believe it will not only improve our practice but also improve the health of our community. My staff has been very excited about this. Still, we were not able to start this major initiative to partner more fully with patients because we have not had the time.

One of my patients recently asked me why we didn't just say no to all of the certifications and recognition programs. This is difficult to do and will get more difficult as we move from fee-for-service to value-based reimbursement models for payment. Most of my colleagues in primary care are having difficulty meeting their practice expenses even without the expenses related to the various certificates and recognition programs available. Sixty percent of primary care practices in North Carolina are small, private practices of fewer than 4 physicians. Every day another physician leaves his or her private practice for employment with a larger group practice or hospital system. Most would prefer to stay in their small practices but are overwhelmed with the amount of work involved in transforming to the new model of care and certifying their transformation.

Many of my colleagues have transformed their practices into patient-centered medical homes but have chosen not to take on the certification process for the reasons I have stated above. They are now penalized financially for this decision, and the penalties will become more burdensome as we move towards value-based reimbursement. Well-intentioned systems now are dishing out cruel and unusual financial punishment to excellent practices that simply don't have the right certificates.

My staff and I have learned several lessons from our experience and have several suggestions for moving forward.

1. The PCMH certification process must be restructured. Each practice should be assigned a NCQA analyst who acts in partnership with the practice to help the practice keep its certification. The analyst should know this practice very well and consult with it quarterly, much like a health care provider guiding a patient in a patient-centered medical home, helping interpret the guidelines and showing the practice how it can best equip itself to achieve certification. This should be a collaborative relationship, not an adversarial one. It should be fashioned after the American Board of Family Medicine's Maintenance of Certification program.

2. We have collaborated with local college and community college health care management departments to provide onsite work experience for their students. They help us with some of our manpower issues related to certification processes, and we give them real-world work experience that serves them well when their education is finished. We have found this to be a win/win experience and could not have maintained our certifications without them. 
3. Many practices could benefit from joining either a clinical integration network or an accountable care organization to help obtain additional support in information technology, contracting, and business/management issues.

4. The various governmental and nongovernmental certification programs should forge connections. Why can't we apply credit for meeting criteria in 1 area to another certification where appropriate? Shouldn't meeting Stage 2 meaningful use requirements mean something to the NCQA? Shouldn't some of our maintenance of certification activities help us meet CMS and NCQA requirements?

The NCQA and the Office of the National Coordinator say they are improving care, but I don't see them improving their recognition processes in ways that relieve the burden of work placed on practices that have active quality improvement programs.

I am considering walking away from the $\mathrm{PCMH}$ recognition process even though I believe in the practice transformation it is intended to guide. I realize that if we decide not to seek ongoing recognition as a $\mathrm{PCMH}$, we will suffer financial hardship, but we have more important business at hand-taking excellent care of patients, improving our practice, and engaging with our patients in a meaningful way.
To read or post commentaries in response to this article, see it online at http://www.annfammed.org/content/13/3/273.

Key words: practice improvement; patient-centered medical home; $\mathrm{PCMH}$; meaningful use; quality indicators

Submitted January 7, 2015; submitted, revised, March 29, 2015; accepted March 29, 2015.

Acknowledgments: The author wishes to thank Wilson Pace, MD, and Elizabeth Staton, MCST, for their assistance.

\section{References}

1. Bodenheimer T, Sinsky C. From triple to quadruple aim: care of the patient requires care of the provider. Ann Fam Med. 2014;12(6): 573-576.

2. National Committee for Quality Assurance. Patient-centered medical home recognition. 2013. http://www.ncqa.org/Programs/ Recognition/Practices/PatientCenteredMedicalHomePCMH.aspx. Accessed Apr 2, 2015.

3. Centers for Medicare \& Medicaid Services. Stage 2. http://cms. gov/Regulations-and-Guidance/Legislation/EHRIncentivePrograms/ Stage_2.html. Accessed Apr 2, 2015. 